\title{
Microstructure and Liquid Phase Separation of CuCr Alloys Treated by High Current Pulsed Electron Beam
}

\author{
Zhiming Zhou ${ }^{a}$, Tao Zhou ${ }^{a}$, Linjiang Chai ${ }^{a *}$, Jian Tua , Yaping Wang ${ }^{b}$, \\ Weijiu Huang $^{a}$, Hongmei Xiao ${ }^{a}, Z^{2}$ ipei Xias ${ }^{a}$ \\ ${ }^{a}$ School of Materials Science and Engineering, Chongqing University of Technology, \\ Chongqing, 400054, China \\ ${ }^{b}$ School of Science, Xi'an Jiaotong University, Xi'an, 710049, China
}

Received: September 8, 2014; Revised: April 12, 2015

\begin{abstract}
Microstructures of $\mathrm{CuCr} 25$ and $\mathrm{CuCr} 50$ alloys treated by high current pulsed electron beam (HCPEB) were investigated in this work. The microstructure and solidification behavior of the $\mathrm{Cr}$-rich phases were characterized by scanning electron microscopy (SEM). Results show that a remelting layer of $3 \sim 5 \mu \mathrm{m}$ is formed on the surface of $\mathrm{Cu}-\mathrm{Cr}$ alloys. The microstructure of the remelting layer reveals that both the fine dispersion of $\mathrm{Cr}$-rich spheroids and the craters appear after HCPEB treatment. This means that metastable liquid phase separation occurs during rapid solidification under HCPEB treatment. In addition, the appearance of relatively large craters in the subsurface of $\mathrm{Cr}$-rich particles with the distance about 5-10 $\mu \mathrm{m}$ provides direct evidences supporting results reported by other researchers in terms of numerical simulation temperature field of HCPEB treatments.
\end{abstract}

Keywords: $\mathrm{Cu}$-Cr alloys, microstructure, liquid phase separation, high current pulsed electron beam

\section{Introduction}

Due to very limited mutual solubility between $\mathrm{Cu}$ and $\mathrm{Cr}$ at room temperature, $\mathrm{Cu}-\mathrm{Cr}$ alloys have been developed to meet increasing industrial requirements for its outstanding combination of high mechanical strength and good electrical conductivities $^{1-5}$. Because of high withstand voltage and exceptional current breaking capacity, $\mathrm{Cu}-\mathrm{Cr}$ alloys have been considered as the best contact material for medium voltage vacuum interrupter ${ }^{4}$. Wang et $\mathrm{al}^{2}$ reported that the grain size and distribution of $\mathrm{Cr}$ phases was critical to reduce chopping currents and sustain high voltage breakdown strength capacity. The finer the Cr-rich phase was, the better the electric contact materials properties could be achieved. In order to further improve electrical and mechanical properties, many efforts have been focused on refining and homogenizing the $\mathrm{Cr}$-rich phase. Rapid solidification is believed to be able to refine microstructure and induce supersaturated solid solution, and thus was used by many researchers to prepare $\mathrm{Cu}-\mathrm{Cr}$ alloys. To date, various methods of rapid solidification have been successfully explored, such as melt spinning ${ }^{4,5}$, splat quenching ${ }^{6}$, gas atomizing and electromagnetic levitation ${ }^{7}$. In these work, fine $\mathrm{Cr}$-rich spheroids were detected in $\mathrm{Cu}$ matrix and attributed to occurrence of the liquid phase separation during rapid solidification.

As a promising high-energy beam surface modification technique, high current pulsed electron beam (HCPEB) has been developed in recent years ${ }^{8}$. Because of good thermal conductivity of metal substrates, main features of HCPEB include rapid heating, melting, vaporization and cooling.

*e-mail: chailinjiang@cqut.edu.cn
Besides, stress waves, shock waves, vibration and other physical phenomena can also be induced on the material surface, which results in extraordinary modification effects, such as improved strength, microhardness, wear resistance and corrosion resistant properties ${ }^{9-11}$. Therefore, by using HCPEB surface modification techniques, many researchers had studied the surface strengthening and surface alloying of steels, magnesium alloys, aluminium alloys, etc ${ }^{11}$.

The failure of vacuum interrupter usually occurs on the surface of $\mathrm{Cu}-\mathrm{Cr}$ contact materials during usage. However, there are few efforts concentrated on the surface modification of the $\mathrm{Cu}$-Cr alloys. As far as the studies of HCPEB concerned, only Lamperti et al. ${ }^{12,13}$ reported the surface microstructure of HCPEB-treated $\mathrm{Cu}-30 \mathrm{Cr}$ alloy by use of secondary ion mass spectrometry and atomic force microscopy. However, mechanism of the craters and cracks has not been analyzed. In the current investigation, the microstructure and crater evolution under HCPEB treatment on the surface modification in $\mathrm{CuCr} 25$ and $\mathrm{CuCr} 50$ alloys were studied with different pulse numbers.

\section{Experimental}

The $\mathrm{CuCr} 25$ (75wt.\%Cu and $25 \mathrm{wt} . \% \mathrm{Cr}$ ) master material was prepared by vacuum induction melting (VIM) while the $\mathrm{CuCr} 50$ master $(50 \mathrm{wt} . \% \mathrm{Cu}$ and $50 \mathrm{wt} . \% \mathrm{Cr}$ ) material was prepared by infiltrating. After polishing, the $\mathrm{CuCr} 50$ alloy was deposited with a $\mathrm{Cr}$ film using FJL560A ultrahigh vacuum magnetron sputtering equipment. An "RITM-2M" type HCPEB machine was applied with pulse numbers of 
30 and 50. The HCPEB treatment was performed under the following conditions: the electron energy $30 \mathrm{keV}$, the frequency $0.1 \mathrm{~Hz}$, pulse duration $2 \mu \mathrm{s}$, and the vacuum $6 \times 10^{-4} \mathrm{~Pa}$. The microstructure and surface morphology after HCPEB treatment were analyzed by JEOL JSM-6460LV scanning electron microscope (SEM). The microstructure of cross-section was etched by $\mathrm{FeCl}_{3}(5 \mathrm{~g}) \mathrm{HCl}(10 \mathrm{~mL})+\mathrm{H}_{2} \mathrm{O}(90 \mathrm{~mL})$ solution.

\section{Experimental Results}

Figure 1a illustrates the initial microstructure of $\mathrm{CuCr} 25$ alloy prepared by vacuum induction melting. As shown in the figure, the matrix is $\mathrm{Cu}$ and the undergrown dendrites are
$\mathrm{Cr}$ phases. Figure 1b illustrates the microstructure of the master $\mathrm{CuCr} 50$ alloy prepared by infiltrating. It comprises coarse $\mathrm{Cr}$ particles distributed in the $\mathrm{Cu}$ matrix.

Surface morphologies of the $\mathrm{CuCr} 25$ alloy after HCPEB treatment is shown in Figure $2 \mathrm{a}$ and Figure $2 \mathrm{~b}$. The microstructure of the remelting layer is significantly different from that of the master alloy (Figure 1). The coarse $\mathrm{Cr}$-rich dendrites cannot be seen. Various microstructure features are observed in Figure 2a: the large craters as denoted by the arrow $\mathrm{A}$; the cracks near the crater as indicated by the arrow B; the splashed layer as indicated by the arrow $\mathrm{C}$. Figure $2 \mathrm{~b}$ indicates that the large $\mathrm{Cr}$-rich spheroids (marked

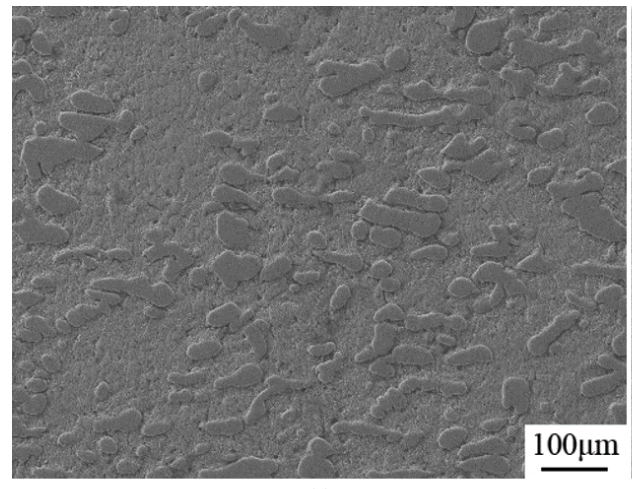

(a)

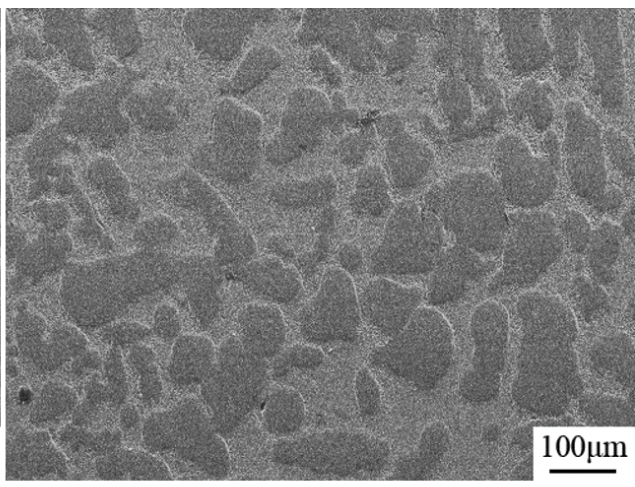

(b)

Figure 1. Micrographs showing the microstructures of $\mathrm{Cu}-\mathrm{Cr}$ master alloy (gray=Cr-rich, light=Cu-rich) (a) $\mathrm{CuCr} 25$ alloy; (b) $\mathrm{CuCr} 50$ alloy.

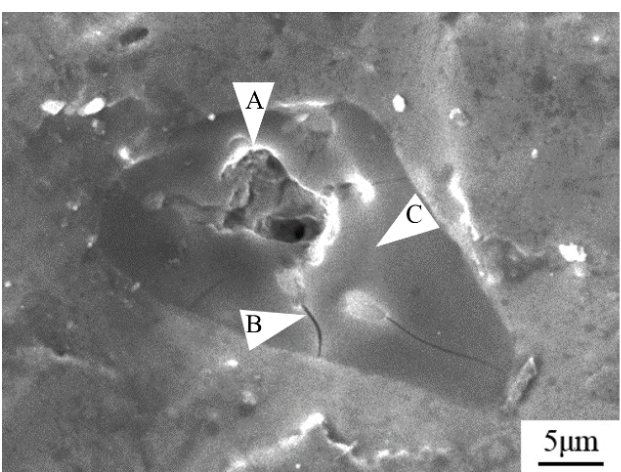

(a)

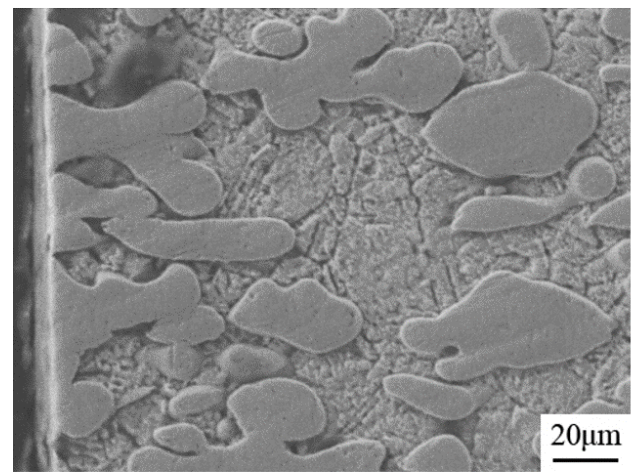

(c)

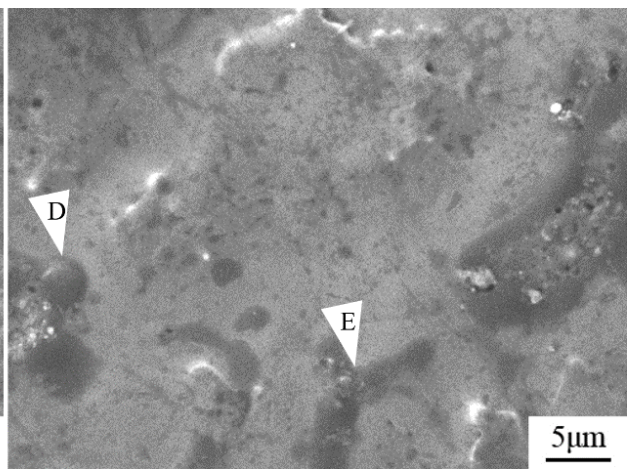

(b)

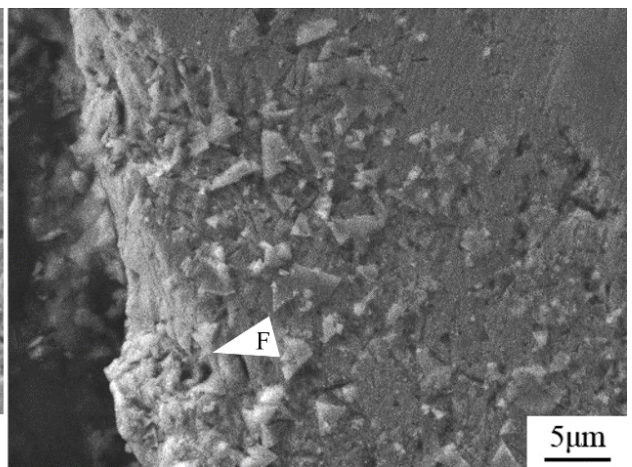

(d)

Figure 2. Micrographs illustrating the microstructures of $\mathrm{CuCr} 25$ alloy after HCPEB treatment with 30 pulses (a) surface micrographs illustrating the craters; (b) Cr-rich spheroids illustrating the liquid phase separation; (c) cross-section micrographs illustrating the remelting layer; (d) cross-section micrographs illustrating the craters. 
by arrow D) and irregular Cr-rich flows (marked by arrow E) occurr. A large number of Cr-rich spheroids with different diameters distribute on the surface. The dimension of $\mathrm{Cr}$-rich spheroids varies from about $100 \mathrm{~nm}$ to more than $2 \mu \mathrm{m}$. Figure $2 \mathrm{c}$ and Figure $2 \mathrm{~d}$ show the cross-section microstructures of the HCPEB-treated $\mathrm{CuCr} 25$ alloy. As can be seen from Figure 2c, a remelting layer with about 3-5 $\mu \mathrm{m}$ in thickness exists. The depth of the craters is about $10 \mu \mathrm{m}$ (denoted by the arrow $\mathrm{F}$ in Figure 2d).

Figure 3 illustrates the microstructure of the $\mathrm{CuCr} 50$ alloys after HCPEB treatment. As shown in Figure 3a, after 50-pulse HCPEB treatment, the number of cracks in $\mathrm{Cr}$ particles increases, and $\mathrm{Cr}$ phase in the $\mathrm{Cu}$-rich matrix is further refined, and the interface of the $\mathrm{Cr}$-rich particles and the $\mathrm{Cu}$-rich phase becomes unclear. Meanwhile, a lot of small $\mathrm{Cr}$-rich spheres appear in the $\mathrm{Cu}$-rich matrix. The cross-section microstructures of alloys are shown in Figure $3 \mathrm{~b}$ and Figure $3 \mathrm{c}$. After the HCPEB treatment, the thickness of remelting layer in $\mathrm{CuCr} 50$ alloys increases to about $3 \sim 5 \mu \mathrm{m}$. As revealed by the arrows $\mathrm{A}$ in Figure $3 \mathrm{~b}$ and $\mathrm{B}$ in Figure 3c, larger craters than cracks in $\mathrm{CuCr} 50$ alloy are about $5 \sim 10 \mu \mathrm{m}$ in the distance from the surface.

The microstructure of the $\mathrm{CuCr} 50$ alloys coated with $\mathrm{Cr}$ films after 50-pulse HCPEB treatment is shown in Figure 4. The cross-section microstructure of the magnetron sputtered
$\mathrm{Cr}$ film can be seen in Figure 4a. It can be found that $\mathrm{Cr}$ layer with a thickness of $2 \mu \mathrm{m}$ is uniformly coated on the alloy surface (marked by arrow A). The surface microstructure of the $\mathrm{CuCr} 50$ coated with $\mathrm{Cr}$ after 50-pulse HCPEB treatment is shown in Figure 4b. Many cracks appear in $\mathrm{Cr}$ particles and the $\mathrm{Cr}$ phases are refined. The interfaces between the $\mathrm{Cr}$ particles and the $\mathrm{Cu}$ matrix become unclear. As indicated by arrow B, a lot of small $\mathrm{Cr}$-rich spheroids exist in the $\mathrm{Cu}$-rich matrix. The cross-section microstructures of $\mathrm{CuCr} 50$ alloys after HCPEB treatment are shown in Figure 4c and Figure $4 \mathrm{~d}$. The remelting layer with $3 \sim 5 \mu \mathrm{m}$ in thickness occur in HCPEB-treated $\mathrm{CuCr} 50$ alloy (marked by arrow $\mathrm{C}$ in Figure 4c). As revealed by the arrow D in Figure 4d, the larger craters than cracks in the $\mathrm{Cr}$ particles are about $5 \sim 10 \mu \mathrm{m}$ in the distance from the surface.

\section{Discussion}

Similar to the $\mathrm{Cu}-\mathrm{Co}^{14}$ and $\mathrm{Cu}-\mathrm{Fe}^{15}$ systems, the $\mathrm{Cu}-\mathrm{Cr}$ system is a liquid metastable binary system with a large positive heat of mixing. Müller ${ }^{16}$ suggested that the $\mathrm{Cu}-\mathrm{Cr}$ system falls into a monotectic type with a stable miscibility gap. Recently, Zhou et al. ${ }^{8}$ proposed a novel monotectic type $\mathrm{Cu}-\mathrm{Cr}$ phase diagram, which displays a stable miscibility gap over compositions between 50.8 and 83.2 wt.\% $\mathrm{Cr}$ at a

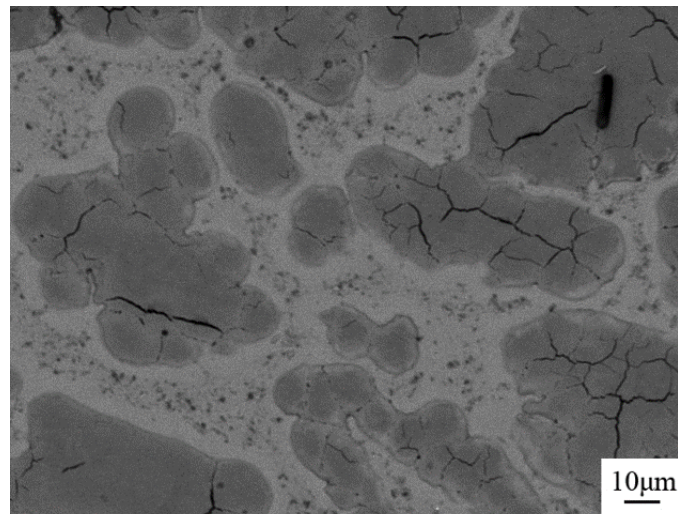

(a)

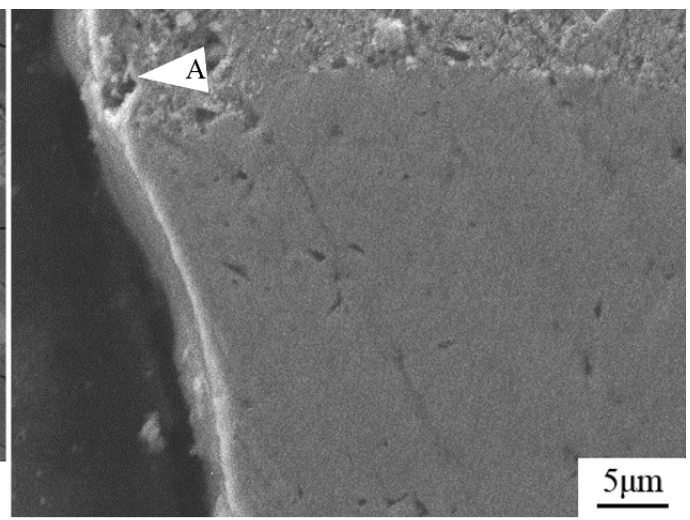

(b)

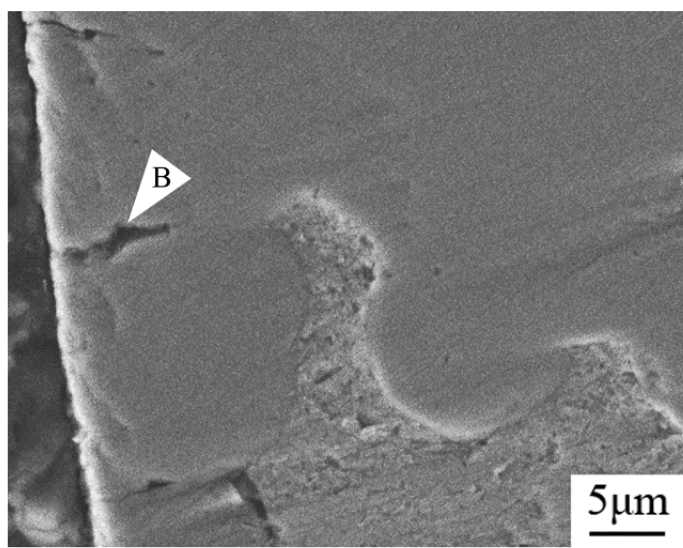

(c)

Figure 3. Micrographs illustrating the microstructures of $\mathrm{CuCr} 50$ alloy after HCPEB treatment with 50 pulses (a) surface micrographs illustrating the cracks and Cr-rich spheroids; (b) cross-section micrographs illustrating the remelting layer and craters in Cu matrix; (c) cross-section micrographs illustrating the craters in $\mathrm{Cr}$ particles. 
monotectic temperature of $2020 \mathrm{~K}$, where there were liquid spinodal lines and dash lines indicated the MG (binodal lines), respectively. When the $\mathrm{Cu}-\mathrm{Cr}$ melt was cooled below a certain temperature, the liquid would enter the MG zone and be separated into $\mathrm{Cu}$-rich liquid and $\mathrm{Cr}$-rich liquid, thus leading to the liquid phase separation ${ }^{8}$. Our previous studies experimentally confirmed that the liquid phase separation will occur in the rapidly solidification $\mathrm{Cu}-\mathrm{Cr}$ alloys by melt spinning, splat quenching and electromagnetic levitation ${ }^{4,6,7}$.

The electron beam will disappear suddenly at the end of every pulse, suggesting a extremely short duration. It means that the melt will cool down and solidify rapidly due to the excellent heat conduction ability of the matrix of $\mathrm{Cu}-\mathrm{Cr}$ alloy. Because of the heat generated by HCPEB bombardment, substantial thermal stress will be produced, thus making it possible to induce cracks in $\mathrm{Cr}$ particles ${ }^{17}$ (as shown in Figure 2a, Figure 3a and Figure 4b). When the electron beams irradiate the original chapped $\mathrm{Cr}$ phases again, coarse craters or cavities will occur in $\mathrm{Cu}-\mathrm{Cr}$ alloys (marked by arrows A in Figure 2a and F in Figure 2d, A and $\mathrm{B}$ in Figure 3, and D in Figure 4d). Moreover, as shown in Figure $2 \mathrm{a}$, splashing phenomenon and cracks are found in the crater. The craters are the consequence of the eruption of melted metal pools ${ }^{18}$. In addition, as shown in Figure $3 \mathrm{a}$ and Figure $4 b$, since the heat of HCPEB can make the alloy surface remelt and solidify repeatedly, the interface between
Cr-rich particles and $\mathrm{Cu}$-rich matrix become fuzzy. In this study, as shown in Figures 2c, 3 b and 4c, the remelting layer with about $3-5 \mu \mathrm{m}$ in thickness is formed in $\mathrm{Cu}-\mathrm{Cr}$ alloys due to the ultra high cooling rate and the extremely large supercooling degree during HCPEB treatment. As a result, all the $\mathrm{Cu}-\mathrm{Cr}$ melts in the composition range enter the MG zone. Therefore, the $\mathrm{Cu}-\mathrm{Cr}$ alloy will not be heated uniformly by the electron beam, which will cause a flow of the melt and the grown Cr-rich droplets will be elongated and swirled (marked arrow D and E in Figure 2b). Another reason for the formation of the $\mathrm{Cu}-\mathrm{Cr}$ remelting layer is splashing. Therefore, Cr-rich sheets (marked by the arrow $\mathrm{C}$ in Figure 2a) also occur in the craters due to the spraying of the molten pool, the high cooling rate and limited melt flow. The cooling rate of the alloy droplets is lower than that of the melts in the pool, and the liquid phase separation and the liquid flow proceed simultaneously. In accordance with previously reported results ${ }^{2,19}$, small Cr-rich droplets form in $\mathrm{Cu}-\mathrm{Cr}$ remelting layer continuously and some extremely fine $\mathrm{Cr}$-rich particles always appear during the liquid phase separation process.

Figure 5 shows a schematic illustration of the HCPEB-treated $\mathrm{Cu}-\mathrm{Cr}$ alloy in this experiment. When the switches of HCPEB equipment are turned on, the surface of $\mathrm{Cu}-\mathrm{Cr}$ alloy is melted and lots of molten pools are formed (as can be seen in Figure 5b). The previous investigation by

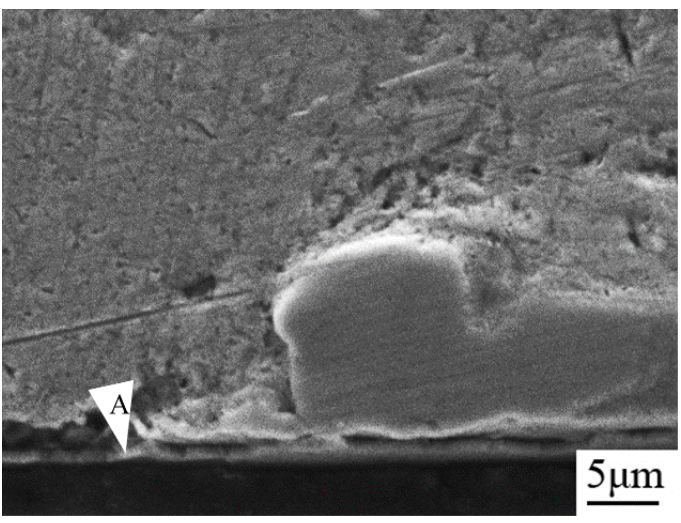

(a)

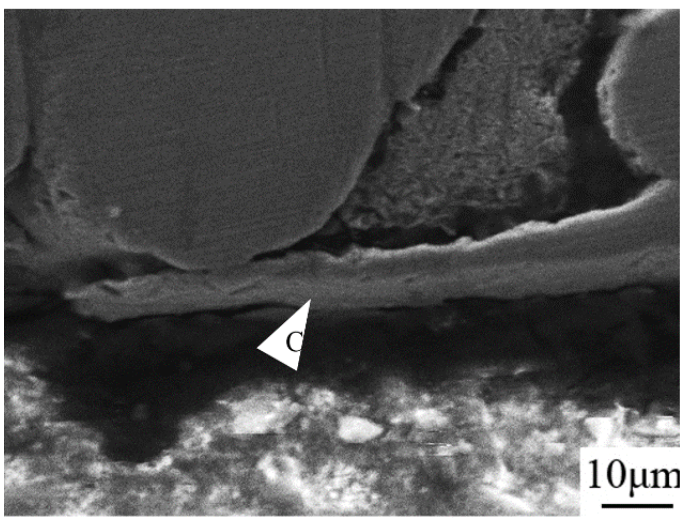

(c)

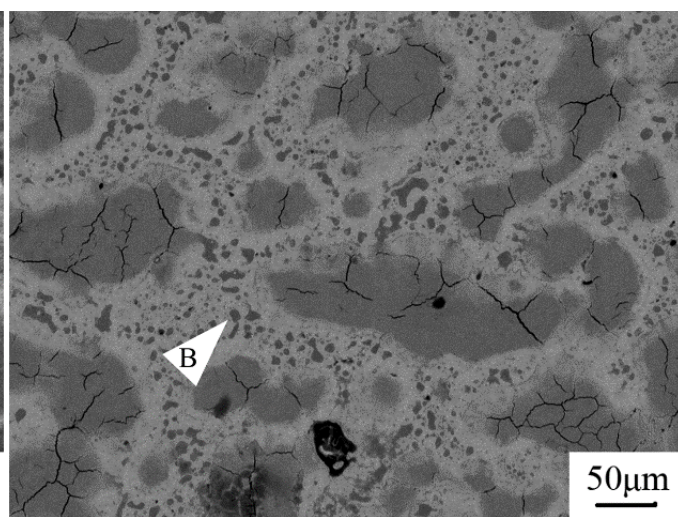

(b)

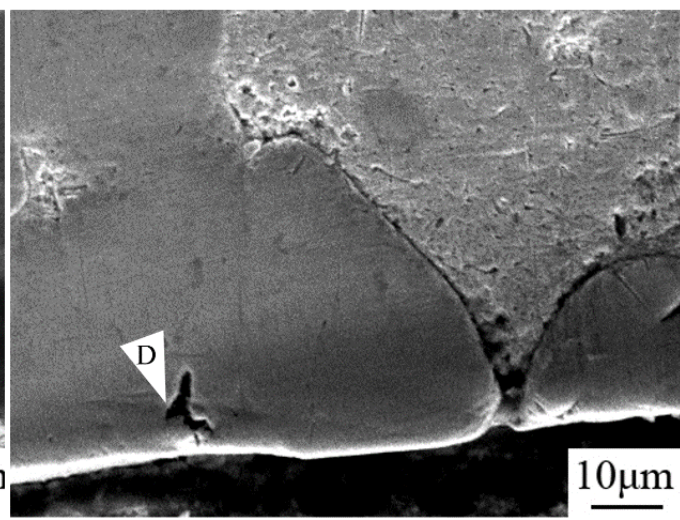

(d)

Figure 4. Micrographs illustrating the microstructures of HCPEB treatment $\mathrm{CuCr} 50$ alloys with $\mathrm{Cr}$ coating with 50 pulses (a) cross-section micrographs illustrating the coating of $\mathrm{Cr}$; (b) surface micrographs illustrating the Cr-rich spheroids; (c) cross-section micrographs illustrating the remelting layer; (d) cross-section micrographs illustrating the craters in Cr particles. 


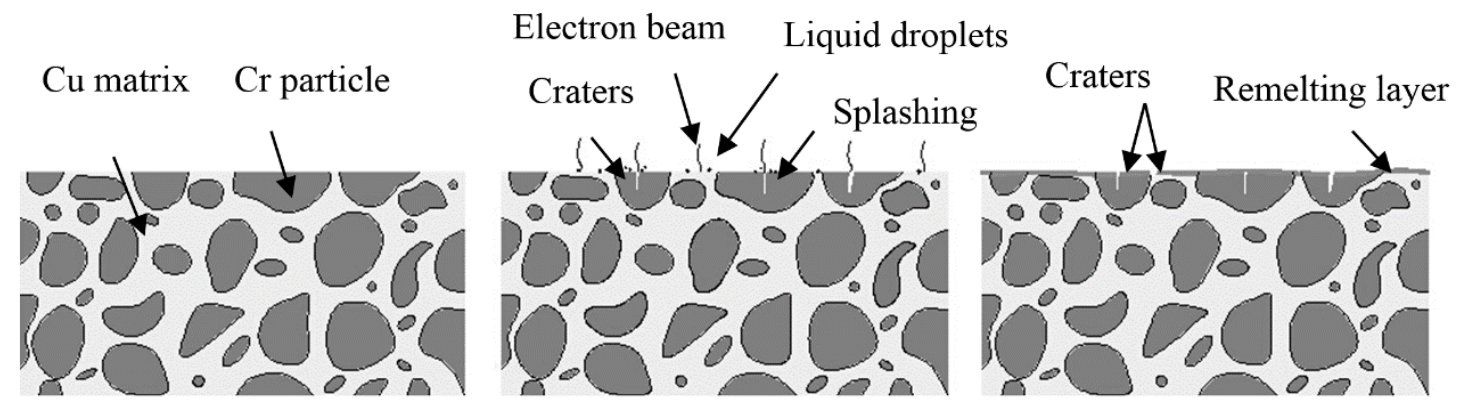

Figure 5. Schematic illustration of the process of HCPEB treatment for $\mathrm{Cu}-\mathrm{Cr}$ alloys (a) master $\mathrm{Cu}-\mathrm{Cr}$ alloy; (b) the splashing and craters during HCPEB treatment; (c) the micrographs after the HCPEB treatment.

Zou et al. ${ }^{17}$ revealed that the highest temperature appeared in the subsurface of alloys after HCPEB treatment. Due to high temperature remelting of subsurface in $\mathrm{Cu}$-rich matrix and $\mathrm{Cr}$ particles, as indicated by arrows A in Figure 3b, B in Figure $3 c$, and D in Figure 4d, the relatively large craters occurred in the subsurface of $\mathrm{Cu}-\mathrm{Cr}$ alloy under the action of thermal stress. The depth of the molten pool is about 5-10 $\mu \mathrm{m}$, which provides direct evidences to the numerical simulation results in Zou et al's studies ${ }^{17}$. During the HCPEB treatment, the $\mathrm{Cu}-\mathrm{Cr}$ alloy will be heated rapidly, and some remolten liquid under the subsurface will be splashed to form the craters, accompanied by the formation of lots of small liquid droplets. When the switches are intermittented, the splashing liquid and droplets will solidify rapidly, then the remelting layer will be formed and the liquid phase separation will occur. The molten pool and liquid phase separation will repeatedly occur. As shown in Figure 5c, the craters and remelting layer occur when the switch is turned off. This refinement of $\mathrm{Cr}$ particles can remarkably improve the dielectric strength according to previous reports ${ }^{19}$. The appearance of Cr-rich spheroids is beneficial to the improvement of the dielectric

\section{References}

1. Slade PG. Advances in material development for high power, vacuum interrupter contacts. IEEE Transactions on Components, Packaging and Manufacturing Technology. 1994; 17(1):96-106.

2. Wang YP and Ding BJ. The preparation and the properties of microcrystalline and nanocrystallineCuCr contact materials. IEEE Transactions on Components, Packaging and Manufacturing Technology. 1999; 22(3):467-472.

3 Zhang C, Wang Y, Yang Z, Guo Y and Bingjun D. Microstructure and properties of vacuum induction melted $\mathrm{CuCr} 25$ alloys. Journal of Alloys and Compounds. 2004; 366(1-2):289-292.

4. Zhou ZM, Wang YP, Gao J and Kolbe M. Microstructure of rapidly solidified $\mathrm{Cu}-25 \mathrm{wt} . \% \mathrm{Cr}$ alloys. Materials Science and Engineering A. 2005; 398(1-2):318-322. http://dx.doi. org/10.1016/j.msea.2005.03.095.

5 Sun Z, Zhang C, Zhu Y, Yang Z, Ding B and Song X. Microstructures of melt-spun Cu100- $\mathrm{x}-\mathrm{Crx}(\mathrm{x}=3.4-25)$ ribbons. Journal of Alloys and Compounds. 2003; 361(1-2):165-168.

6. Zhou ZM, Gao J, Li F, Zhang YK, Wang YP and Kolbe M. On the metastable miscibility gap in liquid $\mathrm{Cu}-\mathrm{Cr}$ alloys. Journal of Materials Science. 2009; 44(14):3793-3799. http://dx.doi. org/10.1007/s10853-009-3511-y. strength of the $\mathrm{Cu}-\mathrm{Cr}$ contact materials. Further studies are needed to understand the remelting layer in $\mathrm{Cu}-\mathrm{Cr}$ alloy.

\section{Conclusions}

A remelting layer with a thickness of $3 \sim 5 \mu \mathrm{m}$ forms on the surface of $\mathrm{Cu}-\mathrm{Cr}$ alloys because of repeated rapid heating and solidifying during the HCPEB treatment. Cr-rich spheroids are observed in the remelting layer, which means that metastable liquid phase separation is involved in the microstructure evolution of rapid solidification in HCPEB-treated $\mathrm{Cu}-\mathrm{Cr}$ alloy. The relatively large craters appeared in the subsurface of the specimens provide direct evidences for the numerical simulation results by other researchers.

\section{Acknowledgements}

This study is financially supported by the National Natural Science Foundation of China under grant Nos. 51101177, 51401040, 51171146 and 51171216, the Natural Science Foundation of Chongqing under grant No. cstc2012jjA245.

7. Zhou ZM, Gao J, Li F, Wang YP and Kolbe M. Experimental determination and thermodynamic modeling of phase equilibria in the $\mathrm{Cu}-\mathrm{Cr}$ system. Journal of Materials Science. 2011; 46(21):7039-7045. http://dx.doi.org/10.1007/s10853-011-5672-8.

8. Zou JX, Zhang KM, Grosdidier T, Dong C, Qin Y, Hao SZ, et al. Orientation-dependent deformation on $316 \mathrm{~L}$ stainless steel induced by high-current pulsed electron beam irradiation. Materials Science and Engineering A. 2008; 483-484:302-305. http://dx.doi.org/10.1016/j.msea.2006.07.179.

9. Zou J, Grosdidier T, Zhang K and Dong C. Mechanisms of nanostructure and metastable phase formations in the surface melted layers of a HCPEB-treated D2 steel. Acta Materialia. 2006; 54(20):5409-5419. http://dx.doi.org/10.1016/j. actamat.2006.05.053.

10. Qin Y, Dong C, Wang X, Hao S, Wu A, Zou J, et al. Temperature profile and crater formation induced in high-current pulsed electron beam processing. Journal of Vacuum Science \& Technology. A, Vacuum, Surfaces, and Films. 2003; 21(6):1934-1938. http:// dx.doi.org/10.1116/1.1619417.

11. Hao SZ, Gao BO, Wu AM, Zou JX., Qin Y, Dong C, et al. Surface modification of steels and magnesium alloy by high current pulsed electron beam. Nuclear Instruments and Methods in Physics Research Section B. 2005; 240(3):646-652. 
12. Lamperti A, Ossi PM and Rotshtein VP. Surface analytical chemical imaging and morphology of $\mathrm{Cu}-\mathrm{Cr}$ alloy. Surface and Coatings Technology. 2006; 200(22-23):6373-6377. http:// dx.doi.org/10.1016/j.surfcoat.2005.11.103.

13. Lamperti A and Ossi PM. SIMS direct surface imaging of Cu1xCrx formation. Applied Surface Science. 2006; 252(6):22882296. http://dx.doi.org/10.1016/j.apsusc.2005.04.015.

14. Munitz A and Abbaschian R. Microstructure of $\mathrm{Cu}-\mathrm{Co}$ alloys solidified at various supercoolings. Metallurgical and Materials Transactions. A, Physical Metallurgy and Materials Science. 1996; 27(12):4049-4059. http://dx.doi.org/10.1007/BF02595654.

15. He J, Zhao JZ and Ratke L. Solidification microstructure and dynamics of metastable phase transformation in undercooled liquid Cu-Fe alloys. Acta Materialia. 2006; 54(7):1749-1757. http://dx.doi.org/10.1016/j.actamat.2005.12.023.
16. Müller R. Arc-melted CuCr alloys as contact materials for vacuum interrupters. Siemens Forschungs-und Entwicklungsberichte. 1988; 17:105-111.

17. Qin Y, Zou JX, Dong C, Wang XG, Wu A, Liu Y, et al. Temperature-stress fields and related phenomena induced by a high current pulsed electron beam. Nuclear Instruments \& Methods in Physics Research. Section B, Beam Interactions with Materials and Atoms. 2004; 225(4):544-554. http://dx.doi. org/10.1016/j.nimb.2004.06.008.

18. Guan QF, Zhang QY, Dong C, Zou G, et al. Effect of structure defects on the surface craters induced by high current pulsed electron beam. Chinese Journal of Materials Research. 2005; 19:496-500.

19. Wei X, Wang JP, Yang ZM, Sun ZB, Yu DM, Song XP, et al. Liquid phase separation of $\mathrm{Cu}-\mathrm{Cr}$ alloys during the vacuum breakdown. Journal of Alloys and Compounds. 2011; 509(25):7116-7120. http://dx.doi.org/10.1016/j.jallcom.2011.04.017. 